\title{
Correction: The Dynamics of Multiscale Institutional Complexes: the Case of the São Paulo Macrometropolitan Region
}

\author{
Leandra R. Gonçalves $\mathbb{D}^{1,2} \cdot$ Pedro Fidelman ${ }^{3,4} \cdot$ Alexander Turra $^{2} \cdot$ Oran Young ${ }^{1}$
}

Published online: 20 January 2021

(c) Springer Science+Business Media, LLC, part of Springer Nature 2021

Correction to: Environmental Management

https://doi.org/10.1007/s00267-020-01379-1

The original version of the article has incorrect affiliation listed twice. The affiliations are such as
1. Bren School of Environmental Science and Management, Santa Barbara, CA, USA

2. Oceanographic Institute, São Paulo, Brazil.

The original article has been corrected.

The original article can be found online at https://doi.org/10.1007/ s00267-020-01379-1.

Leandra R. Gonçalves

leandra.goncalves@usp.br

1 Bren School of Environmental Science and Management,

University of California Santa Barbara, Santa Barbara, CA, USA

2 Oceanographic Institute, University of São Paulo, São Paulo, São Paulo, Brazil

3 Centre for Policy Futures, The University of Queensland, Brisbane, QLD, Australia

4 Centre for Marine Socioecology, Hobart, TAS, Australia 